\title{
ANALISIS KINERJA KEUANGAN DENGAN MENGGUNAKAN METODE COMMON SIZE PADA PT. HOLCIM INDONESIA TBK
}

\author{
ANALYSIS OF FINANCIAL PERFORMANCE \\ USING COMMON SIZE METHOD IN PT. HOLCIM INDONESIA TBK
}

\author{
Riri Rifardi ${ }^{1}$, R. Deni Muhammad Danial ${ }^{2}$, Dicky Jhoansyah ${ }^{3}$ \\ Program Studi Administrasi Bisnis, Universitas Muhammadiyah Sukabumi ${ }^{1,2,3}$ \\ adbisriri@gmail.com ${ }^{1}$
}

\begin{abstract}
Financial statements are used as a tool to find out how the financial performance of the company and can produce useful conclusions. This study aims to determine the financial performance of PT. Holcim Indonesia Tbk, which headlined the 2013-2017 balance sheet and income statement using the common size method. The research method applied in this study is to use descriptive research with a quantitative approach. The results of research conducted indicate the current assets of PT. Holcim Indonesia Tbk is not comparable with the short-term liabilities that are borne by the company, this shows the low liquidity of the company, from solvency, the company uses the capital on the assets of most of the liabilities owned, thus decreasing the level of company sovability and can make a low margin of safety for creditor. Judging from the income statement, it shows that the marketing strategy of the company is not good, as seen from the increase in cost of goods sold and making the gross profit margin decrease. For the company's ability to generate profits, the company's net profit margin from year to year has decreased to a loss in 2016-2017. This shows that financial performance has deteriorated because the company's profitability has always declined to the point of loss.
\end{abstract}

Keywords: Financial Performance, Financial Statements, Common Size Method.

\begin{abstract}
ABSTRAK
Laporan keuangan digunakan sebagai alat untuk mengetahui bagaimana kinerja keuangan dari perusahaan tersebut dan dapat menghasilkan kesimpulan yang bermanfaat. Penelitian ini bertujuan untuk mengetahui kinerja keuangan PT. Holcim Indonesia Tbk yang mengajuk pada neraca dan laporan laba rugi tahun 2013-2017 dengan menggunakan metode common size. Metode penelitian yang diterapkan dalam penelian ini yaitu menggunakan penelitian deskriptif dengan pendekatan kuantitatif. Hasil penelitian yang dilakukan menunjukan aktiva lancar PT. Holcim Indonesia Tbk tidak sebanding dengan liabilitas jangka pendek yang ditanggung oleh perusahaan, hal ini menunjukan rendahnya likuiditas perusahaan, dari solvabilitas, perusahaan menggunakan permodalan pada aktiva sebagian besar dari liabilitas yang dimiliki, sehingga membuat menurunnya tingkat sovabilitas perusahaan dan dapat membuat rendahnya margin of safety bagi kreditur. Dilihat dari laporan laba-rugi menunjukan tidak baiknya strategi pemasaran yang dilakukan perusahaan yang dilihat dari naiknya beban pokok penjualan dan membuat gross profit margin turun. Untuk kemampuan perusahaan dalam menghasilkan laba terlihat net profit margin perusahaan dari tahun ke
\end{abstract}


tahun mengalami penurunan hingga mengalami kerugian pada tahun 2016-2017. Hal ini menunjukan kinerja keuangan semakin memburuk karena profitabiltas perusahaan yang selalu menurun hingga merugi.

Kata Kunci: Kinerja Keuangan, Laporan Keuangan, Metode Common Size.

\section{PENDAHULUAN}

Kinerja keuangan menjadi hal yang penting dan harus terus diperhatikan oleh perusahaan untuk mengetahui apakah sudah tepat apa belum tindakan dan kebijakan yang dilakukan perusahaan dalam usahanya.

Laporan keuangan perusahaan sudah menjadi kebutuhan oleh beberapa pihak karena dapat membantu menemukan kekurangan sehingga perusahaan dapat mengevaluasi dan memperbaiki kinerja keuangan dalam perusahaan tersebut. Oleh karena itu, laporan keuangan digunakan sebagai alat untuk mengetahui bagaimana kinerja keuangan dari perusahaan tersebut dan dapat menghasilkan kesimpulan yang bermanfaat.

Analisis persentase perkomponen atau bisa disebut metode common size yaitu metode yang dipakai untuk membandingkan satu akun tehadap total akun.Analisis ini juga bisa dikatakan sebagai gambaran analisis rasio perbandingan karena dalam nominal rupiah dari setiap unsur laporan keuangan digambarkan dalam bentuk persen dari total. Common Size yang ditinjau dari neraca dapat memberikan gambaran posisi relatif aktiva lancar terhadap aktiva tidak lancar dari total aktiva, juga mengetahui gambaran posisi liabilitas dan ekuitas dari total pasiva.Apabila ditinjau dari laba rugi, metode common size dapat memberikan gambaran distribusi dari penjualan kepada biaya dan laba, hal ini membuat seorang analis dapat mengetahui serta menilai kinerja keuangan perusahaan dari persentase yang telah dihitung.

Objek yang digunakan dalam penelitian ini yaitu pada PT. Holcim Indonesia Tbk yang bergerak dalam industri semen dengan laporan keuangan selama lima tahun yang terhitung sejak tahun 2013 sampai dengan tahun 2017. PT. Holcim Indonesia Tbk merupakan perusahaan yang bergerak di bidang produksi semen. Berikut merupakan grafik laba bersih PT. Holcim Indonesia Tbk selama lima tahun yang terhitung sejak tahun 2013 sampai dengan tahun 2017.

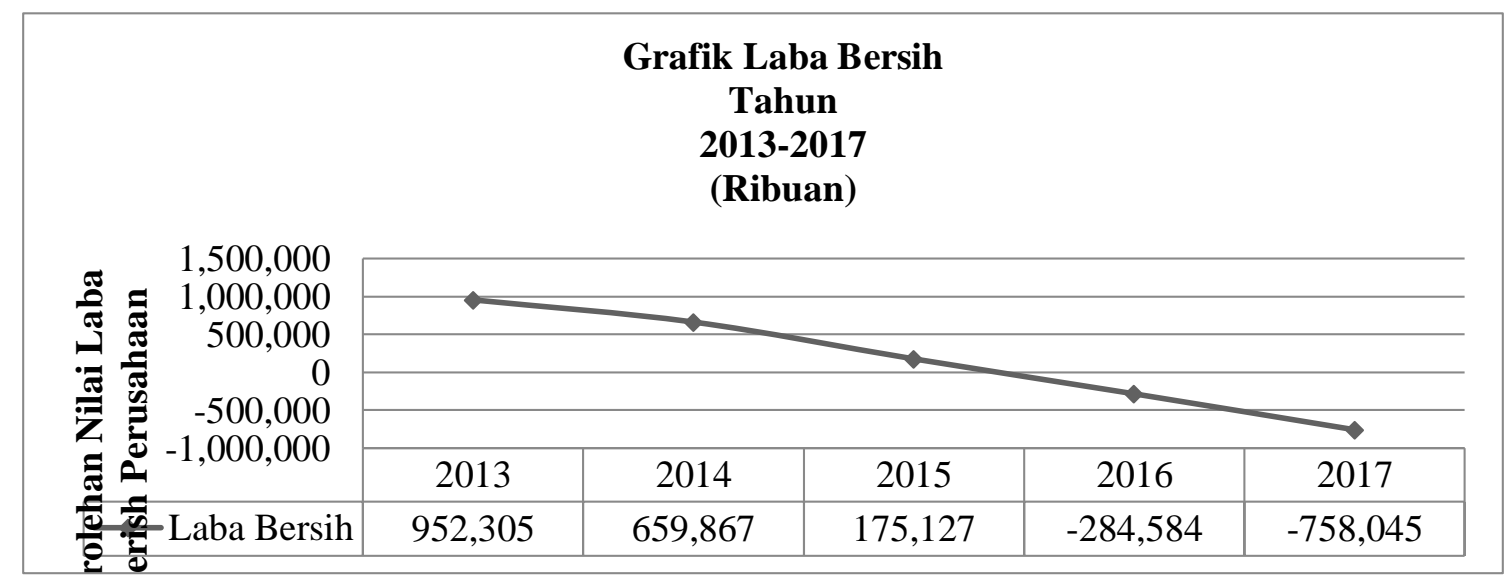

Sumber: Data sekunder diolah, 2018

Gambar 1. Grafik laba bersih PT. Holcim Indonesia Tbk tahun 2013-2017 
Dari grafik diatas dapat disimpulkan bahwa dalam perolehan laba bersih PT. Holcim Indonesia Tbk mengalami penurunan dalam perolehan laba bersihnya yang dilihat selama lima tahun yang terhitung dari tahun 20132017 yaitu mengalami penurunan pada setiap tahunnya hingga mengalami kerugian, tahun 2013 PT. Holcim Indonesia Tbk mempunyai perolehan laba bersih Rp. 952.305,-, mengalami penururan pada tahun 2014 menjadi Rp. 659.867,-, mengalami penurunan juga pada tahun 2015 menjadi Rp 175.127,-, pada tahun 2016 PT. Holcim Indonesia Tbk mengalami kerugian sebesar $\mathrm{Rp}$ 284.584,- dan yang lebih parah lagi pada tahun 2017 sebesar Rp 758.045,-. Dipilihnya PT. Holcim Indonesia Tbk dikarenakan adanya penurunan yang signifikan dari perolehan laba bersihnya. Perolehan laba bersih berhubungan dengan modal, aset, dan hutang perusahaan. Mengetahui kondisi tersebut maka haruslah dilakukan pengengukuran terhadap kinerja keuangan perusahaan terutama dengan menggunakan metode common size agar diketahui pos mana yang harus diberikan perhatian khusus untuk bahan evaluasi pada periode berikutnya.

$$
\text { Menurut Fahmi }
$$

mengemukakan bahwa kinerja keuangan adalah suatu analisis yang dilakukan untuk melihat sejauh mana suatu perusahaan telah melaksanakan usahanya dengan menggunakan aturan-aturan pelaksanaan keuangan secara baik dan benar.

Laporan keuangan menurut Munawir (2004) yaitu sebagai berikut: laporan keuangan merupakan alat penguji dari pekerjaan bagian pembukuan, bukan itu saja laporan keuangan juga sebagai dasar menentukan posisi keuangan perusahaan tersebut dimana dengan hasil analisa tersebut pihak-pihak berkepentingan mengambil keputusan.
Neraca menurut Prastowo \& Juliaty (2002), menyatakan bahwa neraca merupakan sebuah laporan keuangan yang memberikan informasi mengenai posisi keuangan (aktiva, kewajiban, dan ekuitas) perusahaan pada saat tertentu. Laporan laba rugi dikemukakan menurut Subramanyam \& Wild (2010), bahwa: laporan laba rugi (income statement) merupakan pengukur kinerja keuangan perusahaan antara tanggal neraca, laporan laba rugi juga mencerminkan aktivitas operasi perusahaan dan laporan laba rugi menyediakan rincian pendapatan, beban, untung dan rugi perusahaan untuk suatu periode waktu.

Common size menurut Kasmir (2015) "Analisis persentase per komponen merupakan teknik analisis laporan keuangan dengan menganalisis komponen-komponen yang ada dalam laporan keuangan, baik yang ada di neraca maupun laporan laba rugi

\section{METODE PENELITIAN}

Metode penelitian yang diterapkan dalam penelian ini yaitu menggunakan penelitian deskriptif dengan pendekatan kuantitatif untuk menemukan dan mendapatkan jawaban pada masalah yang di teliti dengan menggambarkan kinerja keuangan PT. Holcim Indonesia Tbk pada tahun 20132017 dengan menggunakan metode common size.

Teknik pengumpulan data dilakukan secara sekunder berupa dokumentasi perusahaan dengan memperoleh data laporan keuangan PT. Holcim Indonesia Tbk dari situs www.idx.id berupa neraca dan laporan laba rugi selama tahun 2013-2017.

\section{HASIL DAN PEMBAHASAN}

Perhitungan metode common size yang menggambarkan kinerja keuangan PT. Holcim Indonesia Tbk dan rata-rata 
industri sektor semen yang terdaftar di bursa efek Indonesia pada tahun 2013-
2017 yang dilihat dari neraca pada table dibawah ini:

Tabel 1. Metode Common Size Pada Neraca PT. Holcim Indonesia Tbk

\begin{tabular}{lrrrrr}
\hline Tahun & $\mathbf{2 0 1 3}$ & $\mathbf{2 0 1 4}$ & $\mathbf{2 0 1 5}$ & $\mathbf{2 0 1 6}$ & \multicolumn{1}{c}{$\mathbf{2 0 1 7}$} \\
\hline Kas & $2.521 \%$ & $1.248 \%$ & $3.675 \%$ & $1.639 \%$ & $2.825 \%$ \\
\hline Persediaan & $3.968 \%$ & $3.656 \%$ & $3.186 \%$ & $3.864 \%$ & $4.488 \%$ \\
\hline Aktiva Lancar & $13.998 \%$ & $13.176 \%$ & $15.147 \%$ & $12.483 \%$ & $14.914 \%$ \\
\hline Aktiva Tetap & $86.002 \%$ & $86.824 \%$ & $84.853 \%$ & $87.517 \%$ & $85.086 \%$ \\
\hline Total Aktiva & $100 \%$ & $100 \%$ & $100 \%$ & $100 \%$ & $100 \%$ \\
\hline $\begin{array}{l}\text { Liabilitas Jangka } \\
\text { Pendek }\end{array}$ & $21.9 \%$ & $22.138 \%$ & $23.066 \%$ & $26.875 \%$ & $27.437 \%$ \\
\hline $\begin{array}{l}\text { Liabilitas Jangka } \\
\text { Panjang }\end{array}$ & $19.201 \%$ & $27.965 \%$ & $28.29 \%$ & $32.339 \%$ & $35.894 \%$ \\
\hline Liabilitas & $41.101 \%$ & $50.103 \%$ & $51.356 \%$ & $59.214 \%$ & $63.33 \%$ \\
\hline Ekuitas & $58.899 \%$ & $49.874 \%$ & $48.644 \%$ & $40.786 \%$ & $36.67 \%$ \\
\hline Total Pasiva & $100 \%$ & $100 \%$ & $100 \%$ & $100 \%$ & $100 \%$ \\
\hline
\end{tabular}

Tabel 2. Rata-Rata Industri Metode Common Size Pada Neraca Sektor Semen Yang Terdaftar Di Bursa Efek Indonesia

\begin{tabular}{lrrrrr}
\hline Tahun & \multicolumn{1}{c}{$\mathbf{2 0 1 3}$} & $\mathbf{2 0 1 4}$ & $\mathbf{2 0 1 5}$ & $\mathbf{2 0 1 6}$ & \multicolumn{1}{c}{$\mathbf{2 0 1 7}$} \\
\hline Kas & $26.567 \%$ & $27.562 \%$ & $20.055 \%$ & $12.089 \%$ & $10.641 \%$ \\
\hline Persediaan & $9.215 \%$ & $6.811 \%$ & $6.284 \%$ & $6.475 \%$ & $6.683 \%$ \\
\hline Aktiva Lancar & $56.656 \%$ & $53.178 \%$ & $42.806 \%$ & $36.656 \%$ & $37.510 \%$ \\
\hline Aktiva Tetap & $43.344 \%$ & $46.822 \%$ & $57.194 \%$ & $63.344 \%$ & $62.490 \%$ \\
\hline Total Aktiva & $100 \%$ & $100 \%$ & $100 \%$ & $100 \%$ & $100 \%$ \\
\hline $\begin{array}{l}\text { Liabilitas } \\
\text { Jangka } \\
\text { Pendek }\end{array}$ & $29.963 \%$ & $26.040 \%$ & $23.748 \%$ & $25.577 \%$ & $30.629 \%$ \\
\hline $\begin{array}{l}\text { Liabilitas } \\
\text { Jangka } \\
\text { Panjang }\end{array}$ & $10.326 \%$ & $10.624 \%$ & $12.925 \%$ & $16.295 \%$ & $17.126 \%$ \\
\hline Liabilitas & $40.295 \%$ & $36.663 \%$ & $36.673 \%$ & $41.872 \%$ & $47.753 \%$ \\
\hline Ekuitas & $59.706 \%$ & $63.333 \%$ & $63.327 \%$ & $58.128 \%$ & $52.247 \%$ \\
\hline Total Pasiva & $100 \%$ & $100 \%$ & $100 \%$ & $100 \%$ & $100 \%$ \\
\hline
\end{tabular}

Dari hasil perhitungan metode common size pada PT. Holcim Indonesia Tbk dan rata-rata industri sektor semen yang terdaftar di bursa efek Indonesia pada tahun 2013-2017 menunjukan bahwa aktiva PT. Holcim Indonesia Tbk lebih banyak mengalokasikan dananya pada aktiva tetap terlihat dari perbandingan persentase pos aktiva tetap dan pos aktiva lancer tahun 2013-2017, berbeda dengan rata-rata industri sektor semen aktiva tetap lebih besar dari aktiva lancer hanya pada tahun 2013 dan 2014, 
untuk tahun 2015-2017 aktiva tetap pada rata-rata industri cenderung lebih besar dari aktiva lancar akan tetapi masih di bawah PT. Holcim Indonesia Tbk.

Perolehan aktiva lancar PT. Holcim Indonesia Tbk juga tidak sebanding dengan liabilitas jangka pendek yang ditanggung oleh perusahaan terlihat dari tahun 20132017 hal ini menunjukan tidak baiknya kemampuan perusahaan dalam memenuhi kewajiban jangka pendeknya dengan aktiva lancar yang dimiliki, diperkuat juga dengan perhitungan ratarata industri pada pos aktiva lancar dan liabilitas jangka pendek bahwa tidak ada pesentase pos liabilitas jangka pendek melebihi aktiva lancar yang dimiliki.

Melihat perolehan kas yang dimiliki oleh PT. Holcim Indonesia Tbk, perusahaan belum bisa memenuhi liabilitas jangka pendeknya, terlihat dari persentase kas dan liabilitas jangka pendek PT. Holcim Indonesia Tbk dari tahun 2013-2017, bahwa persentase kas yang dimiliki terlalu minim bila di lihat dengan liabilitas jangka pendek yang di tanggung perusahaan. Begitu pula dengan perhitungan rata-rata industri yang belum bisa menjaga perolehan kas dan kestabilan liabilitas jangka pendeknya.

Pada pasiva PT. Holcim Indonesia Tbk dapat dilihat pada pos liabilitas dan pos ekuitas tahun 2013 bahwa perusahaan mengunakan permodalannya dengan lebih banyak menggunakan ekuitas yang dimiliki, hal ini menunjukan bahwa solvabilitas perusahaan masih baik, tetapi apabila dilihat dari tahun 2014-2017 pada pos ekuitas cenderung menurun dan pos liabilitas meningkat dan dari tahun tersebut perusahaan lebih besar mengunakan permodalannya dari liabilitas hal tersebut membuat beban untuk perusahaan dan rendahnya margin of safety untuk kreditur. Berbeda dengan rata-rata industri yang menunjukan pos ekuitas lebih besar dari liabilitas hal itu menunjukan rata-rata perusahaan dengan sektor yang sama lebih baik dalam solvabilitasnya.

Adapun perhitungan metode common size yang menggambarkan kinerja keuangan PT. Holcim Indonesia Tbk dan rata-rata industri sektor semen yang terdaftar di bursa efek Indonesia pada tahun 2013-2017 yang dilihat dari laporan laba rugi pada tabel dibawah ini:

Tabel 3. Metode Common Size Pada Laporan Laba Rugi Pt. Holcim Indonesia Tbk

\begin{tabular}{lrrrrr}
\hline Tahun & $\mathbf{2 0 1 3}$ & $\mathbf{2 0 1 4}$ & $\mathbf{2 0 1 5}$ & $\mathbf{2 0 1 6}$ & \multicolumn{1}{c}{$\mathbf{2 0 1 7}$} \\
\hline Penjualan & $100 \%$ & $100 \%$ & $100 \%$ & $100 \%$ & $100 \%$ \\
\hline $\begin{array}{l}\text { Beban Pokok } \\
\text { Penjualan }\end{array}$ & $-65.36 \%$ & $-70.726 \%$ & $-76.843 \%$ & $-79.586 \%$ & $-80.024 \%$ \\
\hline Laba Kotor & $34.64 \%$ & $29.274 \%$ & $23.157 \%$ & $20.414 \%$ & $19.976 \%$ \\
\hline Laba Bersih & $9.832 \%$ & $6.958 \%$ & $1.896 \%$ & $-3.009 \%$ & $-8.08 \%$ \\
\hline
\end{tabular}

Tabel 4. Rata-Rata Industri Metode Common Size Pada Laporan Laba Rugi Sektor Semen Yang Terdaftar Di Bursa Efek Indonesia

\begin{tabular}{lccccc}
\hline Tahun & $\mathbf{2 0 1 3}$ & $\mathbf{2 0 1 4}$ & $\mathbf{2 0 1 5}$ & $\mathbf{2 0 1 6}$ & $\mathbf{2 0 1 7}$ \\
\hline Penjualan & $100 \%$ & $100 \%$ & $100 \%$ & $100 \%$ & $100 \%$ \\
\hline $\begin{array}{l}\text { Beban Pokok } \\
\text { Penjualan }\end{array}$ & $-68.460 \%$ & $-70.905 \%$ & $-72.193 \%$ & $-72.656 \%$ & $-75.478 \%$ \\
\hline
\end{tabular}




\begin{tabular}{lrrrrr}
\hline Laba Kotor & $31.540 \%$ & $29.041 \%$ & $27.807 \%$ & $27.236 \%$ & $24.522 \%$ \\
\hline Laba Bersih & $16.356 \%$ & $16.087 \%$ & $14.381 \%$ & $12.046 \%$ & $6.208 \%$ \\
\hline
\end{tabular}

Melihat persentase beban pokok penjualan pada PT. Holcim Indonesia Tbk terlihat berangsur-angsur naik dari tahun 2013-2017 menunjukan tidak baiknya strategi pemasaran yang dilakukan perusahaan dan menurunnya efiesiensi dalam biaya produksi hal itu membuat persentase laba kotorpun (gross profit margin) mengikuti turun pada setiap tahunnya. Pada rata-rata industri pun mengalami hal yang sama pada persentase beban pokok penjualan tetapi persentase beban pokok penjualan Pt. Holcim Indonesia Tbk masih tinggi dibanding dengan rata-rata industri, terkecuali pada tahun 2014 yang berbeda tipis.

Pada persentase hasil akhir kegiatan usaha (net profit margin), perolehan laba bersih Pt. Holcim Indonesia Tbk mengalami penurunan pada setiap tahunnya hingga mengalami kerugian pada tahun 2016-2017, penurunan yang sama terjadi pada ratarata industri tetapi net profit margin pada Pt. Holcim Indonesia Tbk pada tahun 2013-2017 masih berada dibawah rata-rata industri. Hal tersebut menggambarkan kemampuan Pt. Holcim Indonesia Tbk dalam menghasilkan laba bersih semakin tidak baik sehingga kinerja keuangan perusahaanpun semakin tidak baik juga. dengan kata lain profitabilitas Pt. Holcim Indonesia Tbk semakin menurun.

\section{PENUTUP}

\section{Kesimpulan}

Berdasarkan hasil perhitungan dari bab embat dapat disimpulkan bahwa kinerja keungan dengan menggunakan metode common size pada Pt. Holcim Indonesia Tbk tahun 2013-2017 yang dilihat dari neraca menunjukan bahwa aktiva lancar PT. Holcim Indonesia Tbk tidak sebanding dengan liabilitas jangka pendek yang ditanggung oleh perusahaan terlihat dari tahun 2013-2017 hal ini menunjukan tidak baiknya kemampuan perusahaan dalam memenuhi kewajiban jangka pendeknya (likuiditas) dengan aktiva lancar yang dimiliki. Sedangkan dari solvabilitas, perusahaan menggunakan permodalan pada aktiva sebagian besar dari liabilitas yang dimiliki, sehingga membuat menurunnya tingkat sovabilitas perusahaan dan dapat membuat rendahnya margin of safety bagi kreditur.

Adapun kinerja keungan dengan menggunakan metode common size pada Pt. Holcim Indonesia Tbk tahun 2013-2017 yang dilihat dari laporan laba-rugi menunjukan bahwa tidak baiknya strategi pemasaran yang dilakukan perusahaan yang dilihat dari naiknya beban pokok penjualan dan membuat gross profit margin turun. Untuk kemampuan perusahaan dalam menghasilkan laba terlihat net profit margin perusahaan dari tahun ke tahun mengalami penurunan hingga mengalami kerugian pada tahun 20162017. Hal ini menunjukan kinerja keuangan semakin memburuk karena profitabiltas perusahaan yang selalu menurun hingga merugi.

\section{Saran}

Berdasarkan penelitian ini dapat dikemukakan saran untuk Pt. Holcim Indonesia Tbk yaitu diharapkan lebih dapat menjaga kestabilan aktiva yang dimiliki perusahaan. Dan mengoptimalkan aktiva lancar perusahaan agar likuiditas perusahaan semakin baik. Dan di harapkan untuk perusahaan agar jangan terlalu memiliki beban usaha yang lebih besar dari 
modal yang dimiliki perusahaan agar meningkatnya solvabilitas perusahaan. Serta perusahaan senantiasa mengefisiensikan beban pokok penjualannya dari strategi pemasaran dan efisiensi dalam biaya produksi agar meningkatkan persentase laba kotor (gross profit margin). Diharapkan untuk perusahaan dapat meningkatkan persentase laba bersih (net profit margin) agar meningkat juga profitabilitas dari Pt. Holcim Indonesia Tbk.

\section{DAFTAR PUSTAKA}

Fahmi. (2012). Analisis Laporan Keuangan, Cetakan ke-2. Bandung: Alfabeta.

Kasmir. (2015). Analisis Laporan Keuangan. Jakarta: Rajawali Pers.

Munawir, S. (2004).Analisis Laporan Keuangan, Edisi ke-4. Yogyakarta: Liberty.

Prastowo, D. dan Julianty, R.,.(2002). Analisis Laporan Keuangan: Konsep dan Manfaat. Yogyakarta: AMP-YKPN.

Subramanyam, K.R. \& Wild, J.J.,.(2010). Analisis Laporan Keuangan, Buku Satu, Edisi ke10. Jakarta: Selemba Empat. www.idx.co.id diakses tanggal 5

November 2018. 